\title{
José Olympio, editor de Guimarães Rosa
}

\section{DARIO LUIS BORELLI}

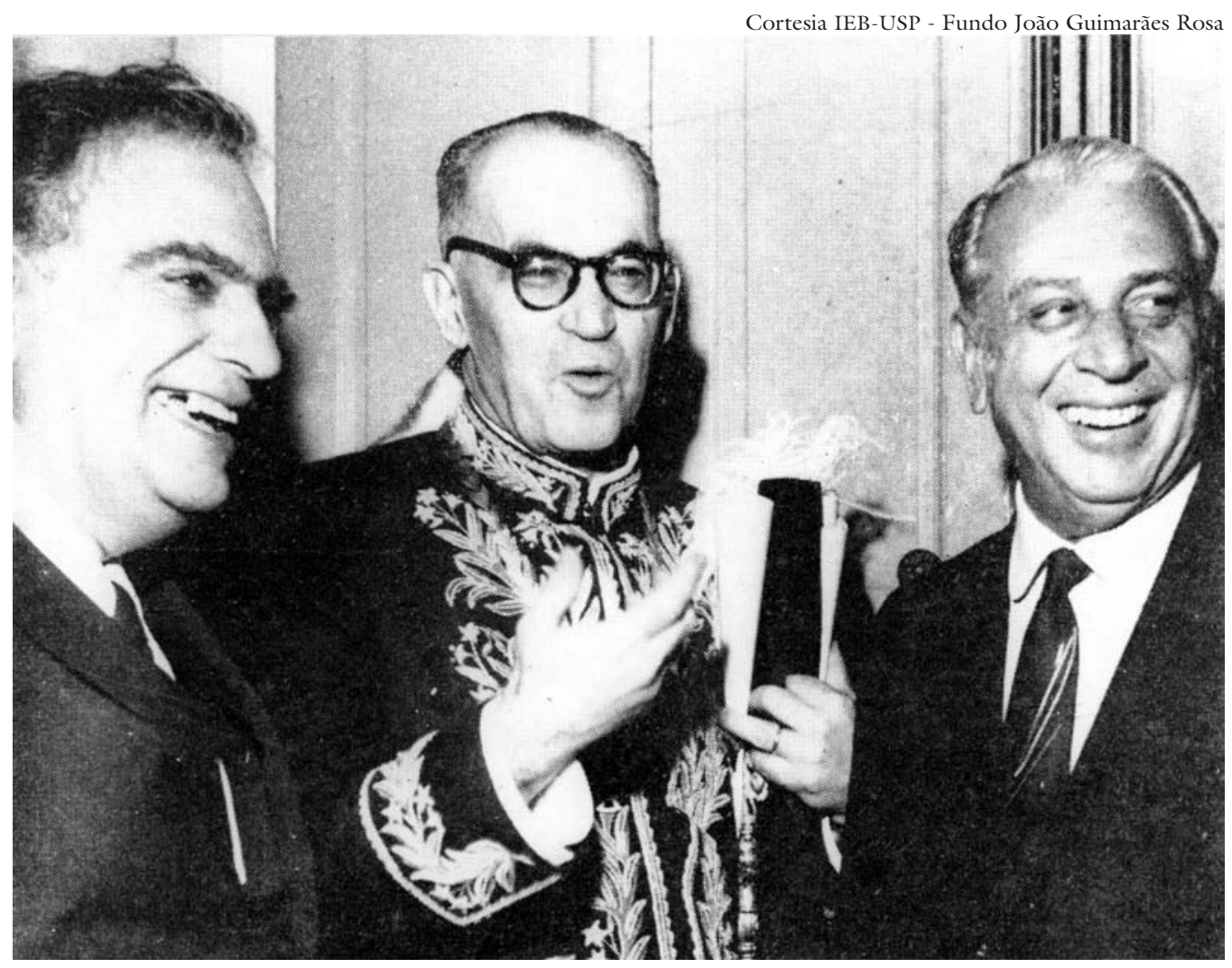

José Olympio, Guimarães Rosa e Negrão de Lima, no dia da posse na ABL, 16 nov. 1967.

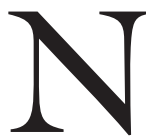

ão Lembrar o nome de José Olympio Pereira Filho, o editor José Olympio, o José, o J. O., na homenagem que ESTUDOS AVANÇADOS rende, nesta edição, à obra de Guimarães Rosa seria um ato irreparável de injustiça. Quer pelo fato de ter sido pelas suas mãos e sob o seu selo que há cinqüenta anos (1956) veio à luz pela primeira vez Grande sertão: veredas e Corpo de baile quer, simplesmente, por ter sido "graças à sua fina sensibilidade para identificar talentos" que a literatura brasileira logrou alcançar a posição de destaque que ocupa hoje no cenário cultural brasileiro e internacional.

Como, porém, fazê-lo? A trajetória de José Olympio e sua intensa atividade editorial desde muito jovem já foram descritas em detalhes e mereceram um capítulo que leva o seu nome em uma das mais importantes obras sobre a história do livro no Brasil, escrita pelo brasilianista inglês Laurence Hallewell. ${ }^{1}$ 
Em reconhecimento ao seu carinho e incansável trabalho a serviço de seu povo, Antonio Carlos Villaça, um de seus amigos e editados, escreveu a sua biografia, ilustrada e com depoimentos inéditos de companheiros e escritores. ${ }^{2}$

A razão pela qual a "Casa" - como era chamada carinhosamente por ele e pelos escritores e intelectuais que freqüentavam a Livraria José Olympio Editora - era considerada um vivo ponto de encontro é o enredo de uma grande crônica que a agora revigorada Editora José Olympio, vinculada ao Grupo Record, do Rio de Janeiro, promete lançar até o final deste ano.

Ocorreu-nos, então, que nessa sutil, porém sincera e justa lembrança, poderíamos reproduzir fac-símiles de dedicatórias de Guimarães Rosa a José Olympio. Depois de uma conversa com Maria Amélia Mello, com quem compartilhamos nossa idéia, surgiu uma pista promissora. Por intermédio da biblioteca do Centro Universitário Claretiano, em Batatais (SP), cidade natal de José Olympio, conseguimos tornar realidade o sonho que acalentávamos desde que ocorreu à editoria da revista compor o dossiê Guimarães Rosa. Em primeira mão, portanto, os leitores de ESTUDOS AVANCCADOS poderão ver verdadeiras relíquias e sentir o reconhecimento de Guimarães Rosa ao zelo de José Olympio com a produção material das obras.

\section{Notas}

1 Laurence Hallewell, O livro no Brasil-sua história. 2.ed. rev. e ampl. São Paulo: Edusp, 2006.

2 Antonio Carlos Villaça, José Olympio: o descobridor de escritores, Rio de Janeiro: Thex Ed., 2001.

Dario Luis Borelli é editor assistente da revista Estudos Avançados, mestre em Jornalismo e Editoração pela Escola de Comunicações e Artes da USP e professor de Comunicação Social das Faculdades Integradas Rio Branco (Fundação dos Rotarianos de São Paulo). @-dariolb@usp.br 

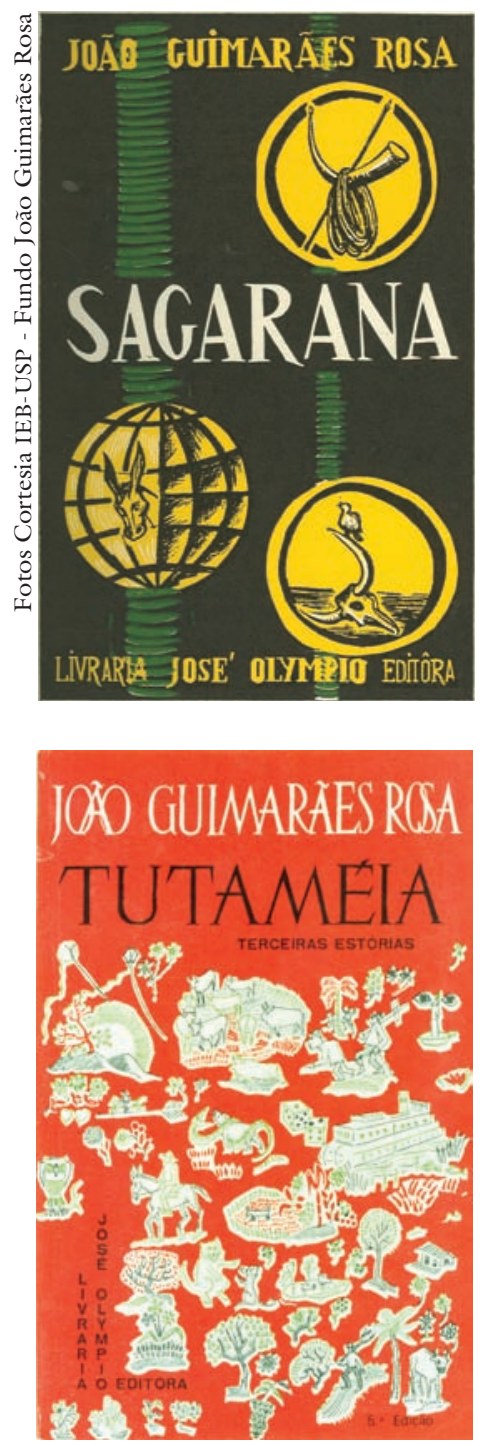
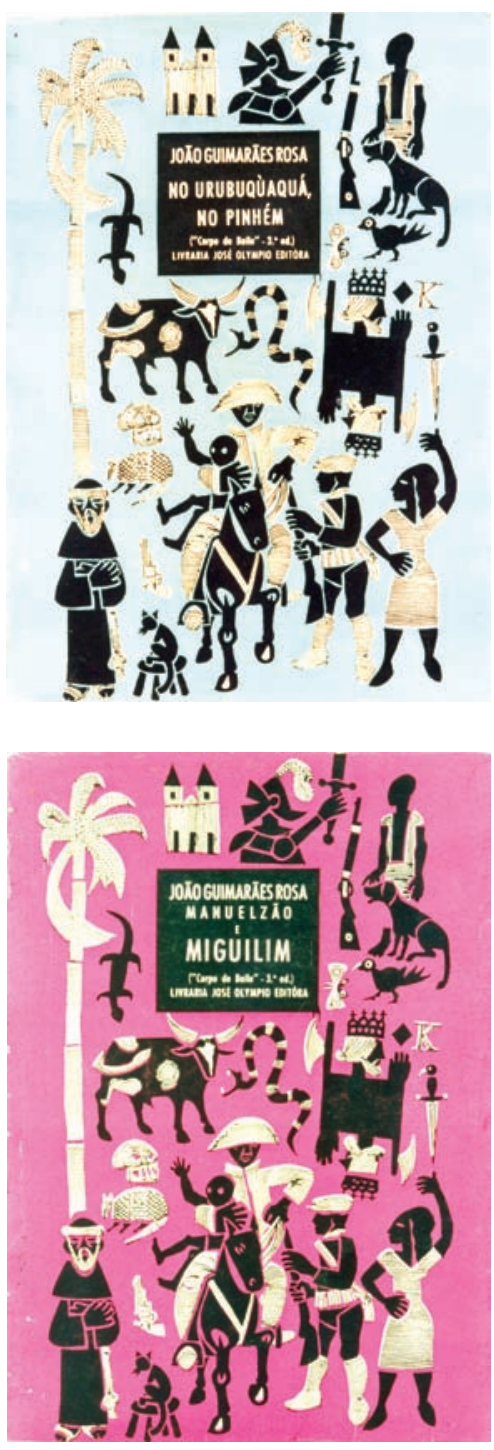

Capas de livros de Guimarães Rosa editados por José Olympio e desenhos de Poty.

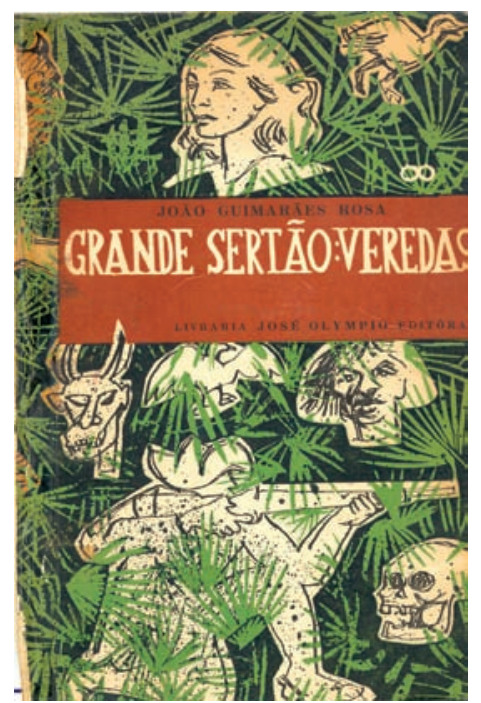

Joāo Guimarāes Rosa

PRIMEIRAS ESTÓRIAS axp

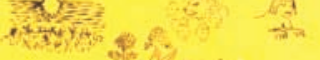

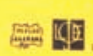
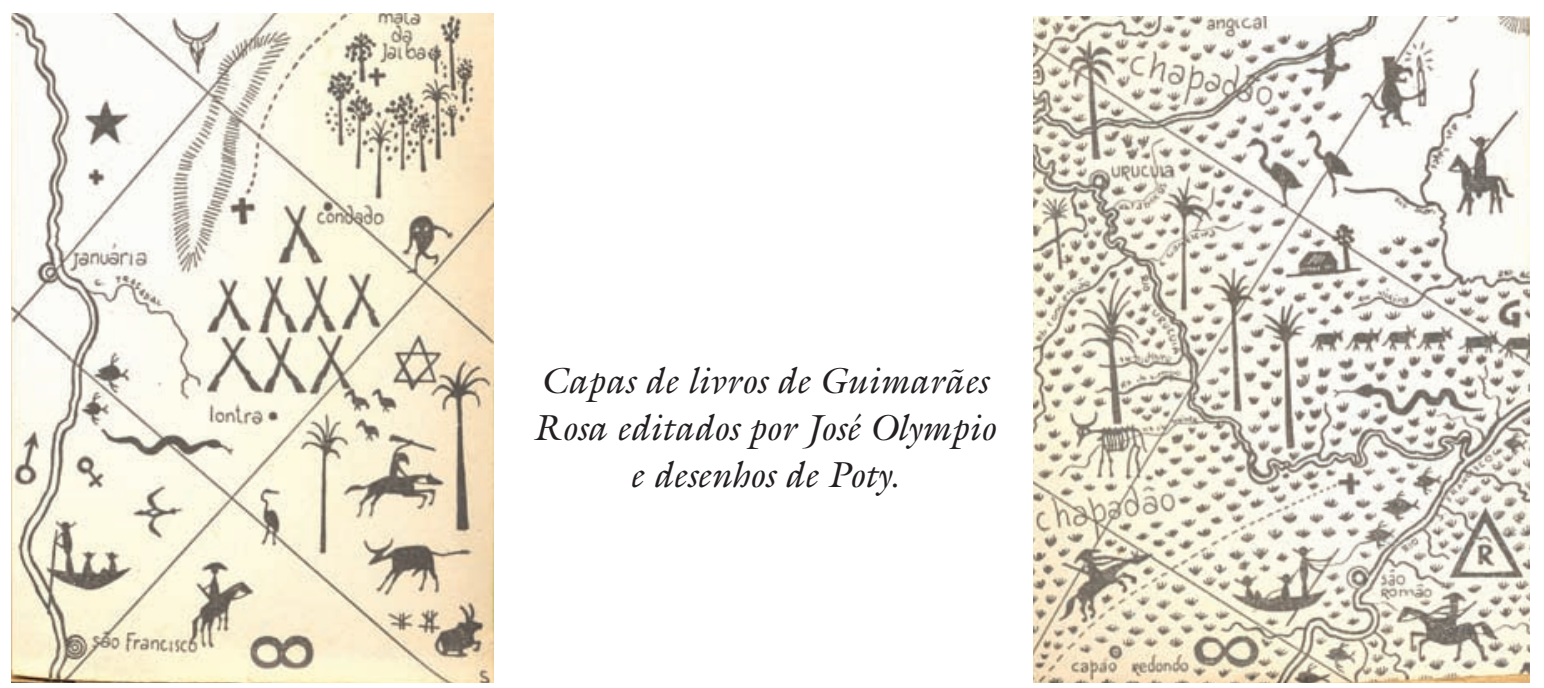


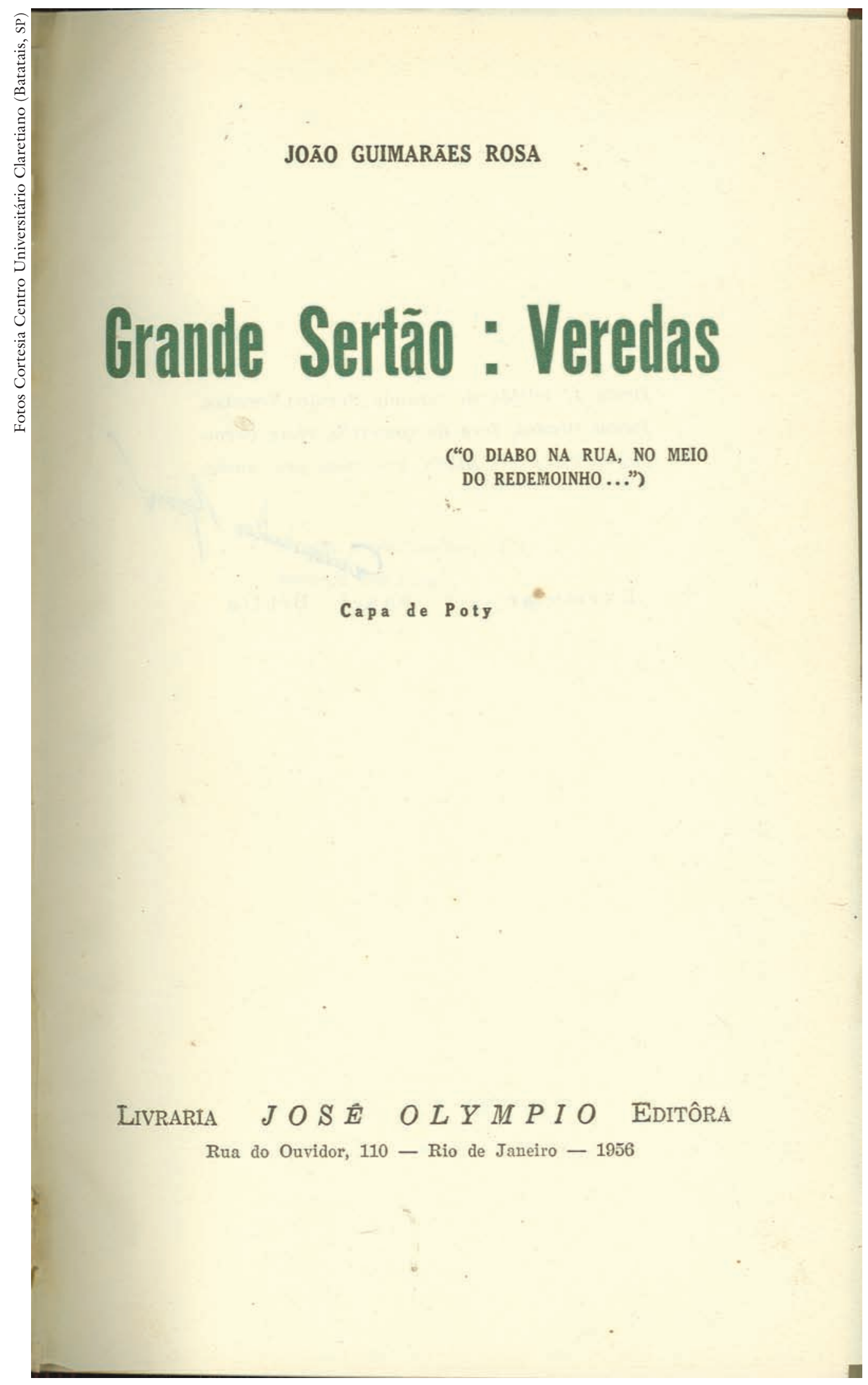


A José Olympio, com a aduircasan:; a gratidaco e a anizade

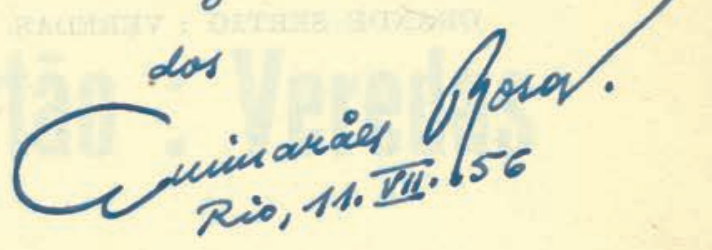

GRANDE SERTÃO : VEREDAS

Estudos Avançados 20 (58), 2006

69 


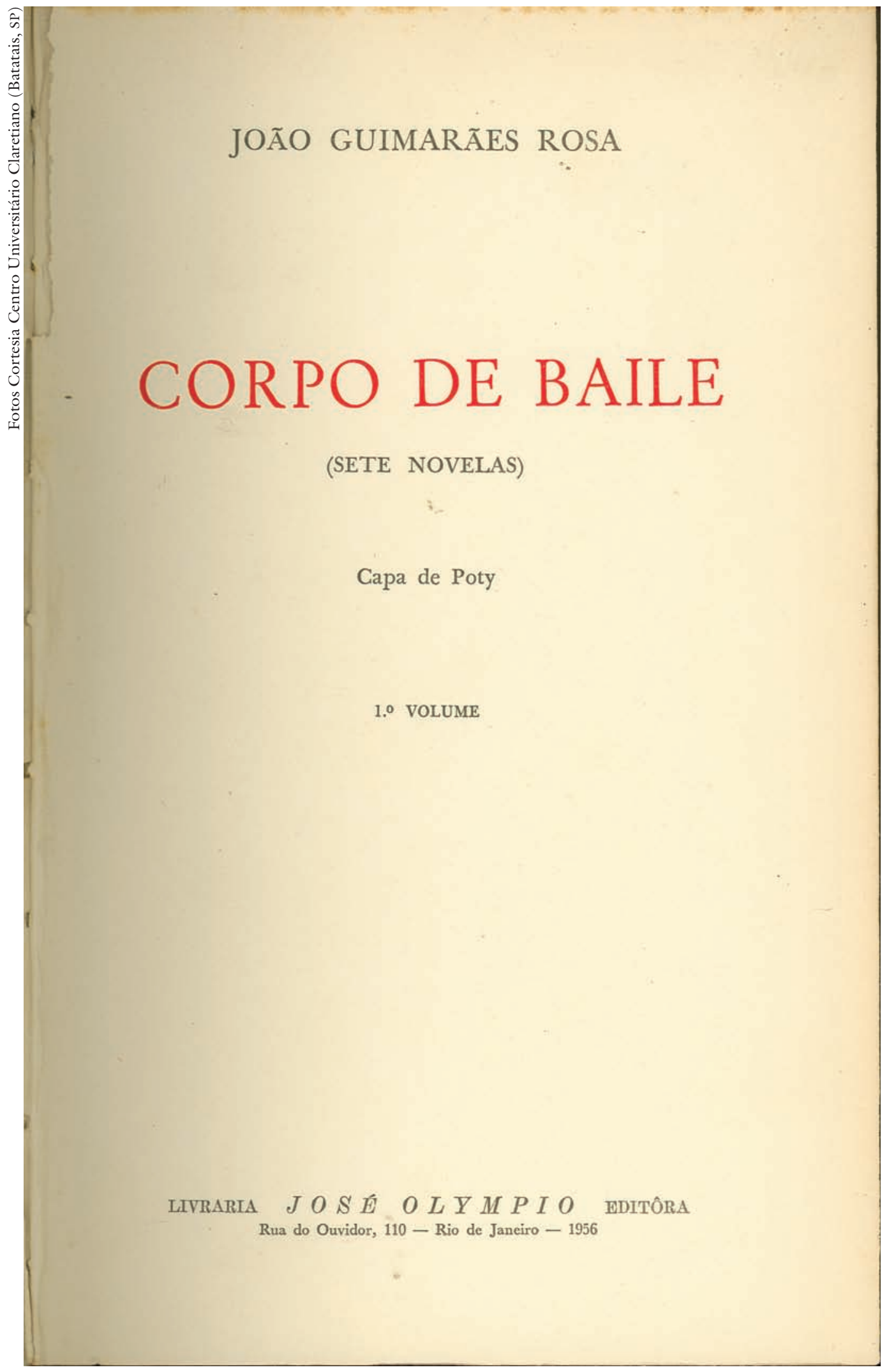


A JOSÉ OLYMPIO

- generosa inteligência e formidável viclor humano a semico da Cultura brasileira, -

sincera homenagem de dodmicação, groctidõo e anizade

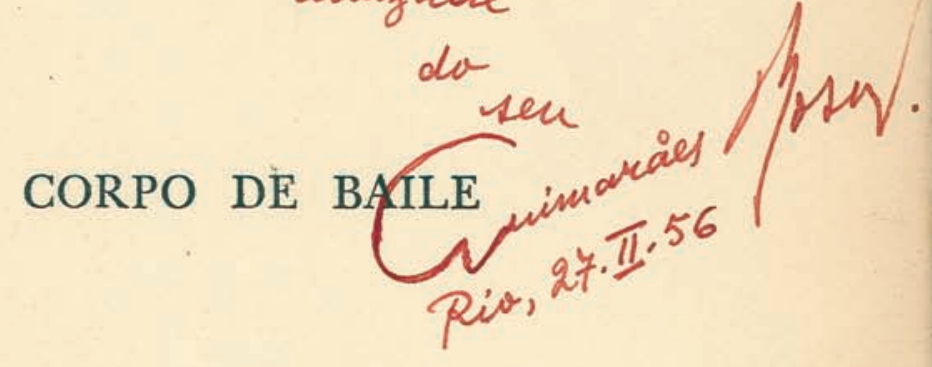

Estudos Avançados 20 (58), 2006

71 
Men caro José- Olympio, Aqui, no poistica dêste noura hives - que Voce quis belo e fêz em apresentascos aduicivel, - caiba a

\section{HOMENAGEM}

mair merecida.

Admiracas. Gratidas. Anvizade. Nar sei dijek suais; sem $e^{-}$ preciso.

Mas, Vocé nemu, nar rabe o quanto e- sen

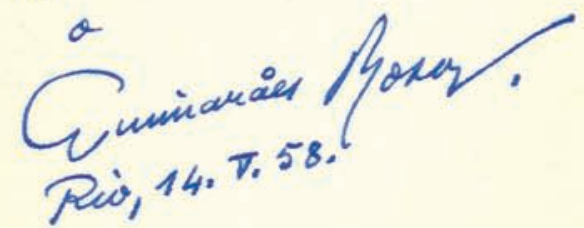

